\title{
The Purposes and Practices of Quality Assurance in Ethiopian Higher Education: Journey, Adaptation and Integration
}

\author{
Kate Ashcroft \\ Cardiff Metropolitan University
}

Philip Rayner

Ashcroft and Rayner Consulting Ltd.

This article includes an analysis of quality assurance in higher education as a travelling idea. Based on interviews and site visits to stakeholders in Ethiopia's higher education, work with Higher Education Relevance and Quality Agency (HERQA) staff over several years, and deskbased research, the idea's "journey" from northern industrial settings to Ethiopia and its adaptation and integration into a developing higher education system is explored. The transfer of ideas is described in a context of a rapidly expanding system and a largely unregulated private market. Ideas of what higher education is for (culture, employability, democracy, entrepreneurialism) and methods of quality assurance (through quality assessment, quality audit inspection, location roles and relationships for quality assurance responsibility) are found to be valued and prioritised differently in Ethiopia. The article explores how ideas are adapted to the operation of differential power amongst stakeholders. Contradictions and dilemmas are described as resulting in creativity and tensions. The article concludes with the challenges faced by the emerging Ethiopian model of quality assessment and assurance, the relevance of different purposes and methodologies to the development context, and the consensus that has emerged from this process about values and processes for quality assurance.

\section{INTRODUCTION}

Although generally acknowledged as a "good thing" there is no clear consensus within northern higher education systems as to the purposes or procedures for quality assurance. Quality assurance is a not a unitary concept: it represents a complex of ideas, approaches and practices that have developed over time and in different contexts to achieve various ends in the interests of various stakeholders. This means that practices and approaches are sometimes in conflict, or at least in tension with each other. Quality can simultaneously mean different things to different people. This can cause confusion and disappointment, and often incoherence, but it also has the advantage that the concept of quality assurance can be questioned, refined and adapted in various ways to meet a variety of circumstances and needs. 
Linked to any concept of quality assurance is the notion of what a university education is for. There has been a worldwide paradigm shift that has taken place regarding the aims and purposes of higher education. This can be expressed as a move from Mode 1, where high-mindedness and "knowledge for knowledge's sake" are paramount to Mode 2 where varieties of stakeholders contribute to decisions about the aims and purpose of higher education (see for example, Rayner, 2005).

In Ethiopia, the idea that quality assurance is necessary and should be developed through an Agency came from the Government and is enshrined in the 2003 Higher Education Proclamation (Federal Democratic Republic of Ethiopia, 2003). The Government faced criticism from its political rivals and some academics for its rapid expansion of higher education and its considerable investment of scarce financial and human resources. It therefore needed to prove to the population at large that this expansion has been successful and has not resulted in a lowering of quality in the universities as some critics have suggested. Although the Government had liberalised the private higher education sector there was still an element of distrust about their motives and standards and so the establishment of a quality assurance agency was seen as a means of managing a rapidly expanding private higher education sector (see for example, Yizengaw, 2007b)

The way that the concept of quality assurance has been introduced and developed has been strongly influenced by various "travelling salesmen" who drew on their own (northern) university sector experience and conceptual frameworks to advise the sector and Government. The main (but not the only) sources of northern influence were the World Bank, which was offering advice and low-cost funding for the development of higher education in Ethiopia. The UK, through VSO (Voluntary Service Overseas) that placed senior UK academics as Acting Director and Vice Director of both the newly created HERQA (Higher Education Relevance and Quality Agency) and HESC (the Higher Education Strategy Centre). Later another senior expert was placed at HERQA as the Agency was developing its processes. The Dutch through NUFFIC (Netherlands Organisation for International Cooperation in Higher Education) projects that were mainly run under the auspices of the Vrije Universiteit Amsterdam to support HERQA and develop pedagogy and strategic capability within HERQA and its sister organizations (the National Pedagogic Centre and HESC). These projects included LMDP, the Leadership and Management Development Project; ASSIST-HERQA, Advice, Strengthening and Support through Investment and Supply of Training for the Higher Education Relevance and Quality Agency; HELP-HESC, The Higher Education Leadership and Policy Support Project for Higher Education Strategy Center; EQUIP, Educational Quality Improvement Programme (see HYPERLINKhttp://www.cis.vu.nl/projects/index.cfm).

Quality assurance as a travelling concept has proved to be "leaky" and malleable as it has moved to Ethiopia. Those ideas that seemed to fit the Ethiopian agenda were incorporated and others were rejected; other Ethiopian ideas have been added. Elements that have leaked out of the model after discussion with the sector include, for example, the notion of a quasi market where HEIs (Higher Education Institutions) compete for student applications and funding; based on outcomes and supported by a funding formula and scoring systems that could be compiled into league tables. Other ideas that fit more easily with the values and practices of the Ethiopian system have been incorporated, for example, the notion of institutional audit against criteria derived through consultation by the sector itself and assessed through peer review. Others were adapted and changed to fit Ethiopia's needs as a developing country with limited staff experience and capability. For example, there was a clear commitment to academic freedom as expressed 
through the location of quality assurance responsibility within the institutions, whist at the same time the institutions have been willing to dilute those academic freedoms through agreement to and participation in a national curriculum framework developed centrally.

In this article, we discuss the ways in which this transfer has occurred - for example, the Ethiopian Government has used the quality assurance concept as a means of regulating a rapidly expanding and largely unregulated private market that has developed, as higher education is no longer exclusively provided by the state. We explore northern ideas of what higher education is for (for example, culture, employability, democracy, entrepreneurialism) and the ways quality assurance is operationalized (for example, through quality assessment, quality audit inspection, location of quality assurance responsibility and the definition of roles and relationships). We look at the ways that particular ideas related to the purposes of higher education are valued and prioritized in the context of a developing country such as Ethiopia. Some of the purposes are seen as relatively unimportant (for example culture) and others are particularly relevant (especially employability, democracy, entrepreneurialism): these have become used but adapted in particular ways in order to define criteria for judgments in the Ethiopian context. In what could be considered a Mode 2 paradigm of higher education, the Ethiopian Government sees higher education as an important plank in its strategy for social and economic development (see Federal Democratic Republic of Ethiopia, 2005).

These ideas about the purpose of higher education have become adapted to government objectives, government control, donor agendas, internal stakeholders and the operation of differential power amongst stakeholders. We conclude that contradictions and dilemmas have developed from the original northern ideas regarding the purpose and processes of quality assurance in higher education. Their conflicting definitions and the ways that they are being implemented, but that the tensions inherent are being dealt with in creative and interesting ways: control vs. autonomy, modernization vs. "government knows best", democracy vs. need to control dissident voices. Dilemmas arise within institutions themselves because of these tensions and the need for managers to work out the hidden as well as overt agendas: but again, there are creative opportunities within these tensions that will be resolved as the sector matures. We also note that the higher education sector in Ethiopia is a fluid entity that is still developing and that HERQA itself is still in a process of maturation and still needs considerable nurturing and resources if it is to successfully fulfill the role it has been given.

\section{METHODOLOGY}

The background research for this article involved three elements: interviews and site visits to stakeholders in the higher educational process, working with HERQA staff in developing the model for quality and standards in the country, and desk-based research into systems for, and models of, quality and standards across the world.

With respect to the first of these elements, between 2004 and 2008 as part of various studies, we systematically interviewed groups of top management, middle management, academic staff and students, employers and donors about their views of the strengths and weaknesses of the system and the models of the student that would support the development of the country, as well as the quality assurance systems and standards that Ethiopian higher education should aspire to.

These interviews were conducted in:

- All of the 9 more established public universities

- 5 private higher education colleges 
- The Civil Service College and the Defence University College

- 5 of the new public universities that were established in 2006

- 35 employers and employer representatives

- 7 representatives from the donor community.

The conclusions that we drew from the interviews we triangulated in order to ascertain the extent of their validity. First, by summarizing the main points of each interview back to the participants so they could correct any misunderstandings on our part, and also by a variety of presentations to the stakeholder groups at workshops, meetings and conferences and through discussions at these events. From the interviews and discussions, we derived a variety of insights about how the models of quality operating over this period were developing, the desire for a quality assurance system but coupled with an initial lack of understanding of how quality could be assessed, and the aspiration for safeguards for standards in the country,

We tested the insights that we had gained from the groups we interviewed with HERQA staff between 2005 and 2009 as we worked through various models of quality assurance that might be used in Ethiopia, and tested these with stakeholders at a variety of workshops. In addition, we looked at models of quality assurance that operated across the developed world and in less developed countries such as South Africa and India. We analyzed documents produced by the Ethiopian Government related to the aims, plans and purposes of education and their poverty reduction strategy.

\section{BACKGROUND}

Quality assurance has become a key idea in northern higher education. It is seen as the most important element in accountability for public funding and to protect a variety of stakeholders (see for example, Brown, 2001). It is also generally accepted by universities as a means of providing some public reassurance, whilst protecting the university's essential autonomy. One of the problems this concept has experienced is its multiple meanings and purposes and (sometimes) a confusion with quality control and quality enhancement.

Quality assurance is closely related to quality control: an idea that, in the north, travelled from manufacturing to business and thence to education. In the manufacturing context, it is the means to ensure that each manufactured item is standardized, so that it does not exceed minimum tolerances of variation from a "norm". This is generally in terms of matters such as exact size, materials and strength. Factories will have "testers" who take samples from a production line and subject them to various measurements and tests to ensure that the process is producing consistent products that are "fit for purpose". These ideas developed by business and manufacturing, have been taken by Governments and turned into legislative and other standards that often relate to the acceptability of processes as well as products. For example, in the UK, the Trading Standards Institute has been developed to support businesses in this respect and the Supply of Goods and Services Act (1982) protects the interests of consumers by establishing minimum levels of acceptable standards. In addition, businesses and service providers have been keen to demonstrate to potential customers and staff that they go well beyond their legal requirements in terms of standards and voluntarily undergo assessments by inspectors and others to meet such expectations.

When business started to use the idea of quality assurance, it took the notions of standardization and measurement and applied them to processes that were more inherently 
subjective and conducted in situations that are much more various and unstable than a factory production line, such as service levels and the use of resources. Quality assurance thus became a metaphor that helped business managers to control the human environment to create a standardized service and service culture. As the role of higher education in northern countries has changed, so HEIs in the UK and elsewhere have seen increased competition for academic staff who can bring research grants with them and students who bring funding for teaching and learning with them. They too increasingly use quality standards to improve their services and give them a marketing edge, for example by achieving Investors in People accreditation for the management and training of staff or ISO 9001 (International Organization for Standardization Accreditation for Quality Management). HEIs also market themselves by highlighting their (high) ranking in various league tables.

Governments as well as students and staff have a vested interest in the quality of the education they fund. In northern systems, some concepts from quality assurance of business processes have been adapted and applied to education to ensure that they are fit for purpose. This has proved problematic when it comes to teaching, where "correct" methods and results are highly debatable. To overcome this problem, inspection and other forms of Government controlled or funded systems have been developed. In the Netherlands, QANU (Quality Assurance Netherlands Universities) or, in the UK, OFSTED (the Office for Standards in Education, Children's Services and Skills) which inspects schools and children's services and the TDA (the Teacher Development Agency) that determines the content of teacher training courses as well as other duties.

The development of private higher education and the extension of open and blended learning formats have presented challenges to Governments with respect to how to ensure the quality of higher education. They have responded in a variety of ways. With respect to general education the trend has been to regulation (for instance, through imposing a national curriculum) which can be enforced through inspection. This has tended to be seen as inappropriate for higher education where academic autonomy has been jealously guarded. This led to the "evaluative state" replacing the "regulatory state" at least as far as higher education is concerned:

"The regulatory state prescribes the processes by which institutions function to produce outputs through an array of detailed legal instruments including laws, line-item budgets, guidelines and rules. The evaluative state, on the other hand, sets forth institutional missions, qualitative and quantitative input and output targets and confines itself to evaluating achievements, while allowing institutions to determine their own ways of achieving those missions and targets. Among the major changes that occurred were lump- sum budgets, resource diversification through the introduction of or increase in tuition fees, and provision of incentives for income generation, increased institutional powers, including professorial appointments and discretion in financial matters."(INQAAHE, QAP, Module 1 unit 2, 2009, p.13).

The differences with industry and business are still more marked when one comes to the higher education culture. Higher education is not a standardised forum, nor does it aspire to be. Universities are quite rightly jealous of their autonomy and as one of the pillars of a free society and so they resist government interference in their curriculum and processes. However, they are aware of the need to reassure stakeholders, particularly government funders and, increasingly, 
students who now share the cost of their higher education and so demand "value for money" and appropriate outcomes, often expressed in the form of a guarantee of a "good job". One solution has been to establish systems that are run by the universities themselves to review and report on standards, sometimes with partial or complete government funding. An example of such a peer review system is that run by the QAA (the Quality Assurance Agency) in the UK.

In developing quality assurance systems for higher education, northern systems have tended to take account of the purposes of higher education and, in particular, the protection of democracy and the creation of new knowledge, both of which require academic freedom and a certain non-conformity within the system. At the same time, funders such as government are keen to ensure that the funding they provide contributes to the employability of students and that universities are an engine for entrepreneurship (see for example, HEFCE, 2008).

This diversity of university roles leads to tensions between establishing standards and recognizing different missions. Northern governments have sometimes tried to resolve these dilemmas through neo-liberal ideas of education as a "public good" that needs to be regulated through a quasi-market. This has raised dilemmas as to how to create this market. In the UK this has been partially resolved by the requirement for universities to collect and publish performance data and their compilation into league tables that include matters such as employability outcomes, completion rates, QAA scores and research assessment scores and the development of a funding formula and research funding that rewards outcomes.

The work of the university is creative and is about new ideas and new ways of doing things. One of the strengths of the quality assurance model is the way that it can be adapted and changed to meet the very challenging environment of the university. The downside of this adaptability is the confusion it can lead to about the definition of terms and its key purposes. In short, even in its home in the northern developed world, in the context of universities, quality assurance means different things and serves different purposes for different sets of people. These differences matter because they lead to different outcomes, and can be used to make misleading comparisons and faulty policy decisions that, if they are ignored, produce a distorted picture that can be used for unfortunate ends. In the course of this article, we look at the different purposes and forms of quality assurance and some of the compatibilities and choices that have been made in utilizing the concept in Ethiopia.

\section{CONTEXTUAL ISSUES}

Higher education has only really been available in Ethiopia since the early 1990s when the current Government, the Ethiopian People's Revolutionary Democratic Front (EPRDF) led by Meles Zenawi, overthrew the hard-line Marxist Derg regime (1974-1991). Haile Selassie University was established in 1961 and in 1974 the name was changed to Addis Ababa University (AAU). This was the only university in Ethiopia until 1985 when Alameya University was established.

Higher education has increasingly become an important part of the EPRDF's attempt to improve economic and social conditions in the country and is seen as one of the ways of spearheading regional identity and autonomy in a country with over 80 languages and dialects (see HYPERLINK http://www.aau.edu.et/ies/). The expansion from 2 federal universities to 22 in the last decade and the planned expansion by opening another 10 may be partially explained by the need for a larger trained work force. However, the motivation and their location also relate to the need for national unity: universities established within the regions help each other to have 
both a measure of autonomy and self respect, but also a stake in the national identity as well as being a catalyst for local economic development through increased demand for goods and services in the local community.

Thus, in common with many countries throughout the world the government of Ethiopia is in the process of radically expanding its higher education sector. This expansion is termed "massification", although the percentage of those of the available cohort who actually attend higher education is still low at about 3\%, compared with a Sub Saharan average in 2007 of 6\%, $59 \%$ in UK and $60 \%$ in the Netherlands (UNESCO, 2011). The huge expansion of student numbers is often located in new regional universities and the vibrant private HE system.

Despite the nascent nature of Ethiopia's expansion it is nevertheless quite radical in comparison to the size of the existing higher education sector (in the past few years, doubling again and again each year) and to the size of Ethiopia's public purse. Ethiopia is one of the world's poorest countries and the expansion of higher education is a considerable investment, both financially and politically, and is therefore a considerable risk for the Government.

One of the ways in which the Government is trying to mitigate these risks is though the establishment of some kind of transparent and objective quality assurance process. It requires monitoring for accreditation purposes (especially important in regulating the expanding private sector) and also to ensure that quality does not suffer to an unknowable extent: such a rapid expansion puts pressure on the limited pool of capable and qualified people and systems to manage the institutions. At the same time, Government cannot micro-manage such a diverse and large system (as it has done in the past) and so must balance central control with institutional autonomy. It has changed the operation of power within Government and devolved considerable freedoms and responsibilities to the universities. It has looked to the northern developed countries for ways to manage this and has used concepts of quality and quality assurance, operated through quasi-autonomous sector support units, as the basis for a relatively "hands-off" system of regulation and control. Recognizing the importance of quality and relevance in this new context, the 2003 Higher Education Proclamation established HERQA.

It was hoped that this organization would mitigate political risks by showing that the newly expanded system is "producing quality" whilst at the same time providing many more students with the opportunity for post-secondary education, increasing the level of skills and professionalism amongst the population and helping to meet the country's development needs.

\section{PURPOSES FOR HIGHER EDUCATION IN THE ETHIOPIAN CONTEXT}

The rapid expansion of higher education in Ethiopia means that many of the existing ideas about higher education are in need of re-assessment and/or change. These ideas include questioning the purpose of higher education, who it is for, how it is paid for, and so on. In 1997 the Ministry of Education published a document Future Directions of Higher Education in Ethiopia (Federal Democratic Republic of Ethiopia, 1997) which, according to Yizengaw, "has played a significant role in the planning and implementation of expansion and reform agendas of the higher education sector in subsequent years". In this document some of the major challenges and problems of higher education in Ethiopia are identified, including "Problems of quality and relevance of programs of studies and research" (Yizengaw, 2007a, p.35).

In 2002 both the Government's Capacity Building Strategy and Programs and the Ministry of Finance and Economic Development's Sustainable Development and Poverty Reduction Programme and in 2005 its Plan for Accelerated and Sustained Development to End Poverty 
(PASDEP) identified Higher Education as crucial for the country's future development (Federal Democratic Republic of Ethiopia, 2002a, 2002b and 2005b). Over recent years there has been a process of defining what exactly the purpose of higher education is and what benefits it offers in return for the investment of scare economic and human resources (see http://www.eaie.org/pdf/ F82art6.pdf). According to the Education Sector Development Program-III (ESDP-III), the major goals of higher education in Ethiopia are:

"To develop responsible and competent citizens who meet the quantitative and qualitative demand for a high-level trained labor force based on the socioeconomic development needs of the country. To ensure democratic management and governance in Higher Education system. To set up cost effective, efficient and results-oriented system in order to develop an appropriate range of modern and effective human resources management and resource practices and procedures. To develop the volume, quality and relevance of research and consultancy services which are necessarily directed to the needs of the country." (Federal Democratic Republic of Ethiopia, 2005a, p.23).

The recent Proclamation (Federal Democratic Republic of Ethiopia, 2009) has an even longer list of objectives for higher education. Many of these overlap with the previous 2003 Proclamation, but others relate to technology transfer; freedom of expressions based on reason and rational discourse; community and consultancy services; participation of stakeholders; institutional autonomy with accountability; upholding justice, fairness and the rule of law; multiculturalism; and the expansion of access. Thus the expansion of higher education is intended potential to fulfill various economic and social imperatives. In Ethiopia over $82.6 \%$ of the population is engaged in subsistence farming.

Without a substantial middle class to tax, infrastructure investment can only occur though loans. However, in the past, capacity building based on loans led to a substantial debt legacy with devastating effects of the lives of the most vulnerable people. In response to these problems, in 1996, the World Bank launched the Debt Initiative for Heavily Indebted Poor Countries (HIPC), which created a framework for all creditors, including multilateral creditors, to provide debt relief to the world's poorest and most heavily indebted countries, and thereby reduce the constraint on economic growth and poverty reduction imposed by the debt build-up in these countries. Details can be found at the website "http://web.worldbank.org/". Higher education may be one way of creating a larger middle class. It may also be seen as a way for the country to produce the professionals it needs to help the populace to lead more productive lives: teachers to raise levels of literacy, agricultural and civil engineers to create more productive ways of feeding and providing economic necessities for the population and health professionals to help combat threats to the health of the population such as HIV/AIDS.

In 2004, the then Vice Minister for Higher Education in Ethiopia, Dr Teshome Yizengaw set out his vision for higher education reform (Yizengaw, 2004). Echoing other commentators such as the World Bank (2004), he described higher education's role as central to increasing and diversifying knowledge and competitiveness in global and knowledge-based markets, as well as the protection of democratic culture and society. Yizengaw characterized Ethiopian higher education before reform as failing to participate in the development effort, blaming the Derg regime for undermining higher education institutions" confidence and quality. He argued that this caused a lack of vision, resource constraints and a lack of equality of opportunity. $\mathrm{He}$ 
described Ethiopian higher education in 1994 as characterized by an extreme top-down approach, with Government determining matters such as curriculum and faculty appointments. Eventually, some autonomy over academic matters was given to HEIs, but until recently, little was allowed over financial and administrative matters. The 2003 Higher Education Proclamation changed this context and allowed institutions certain financial and academic freedoms: the 2009 Higher Education Proclamation has an entire section on the specification of increased autonomy in the areas of curricula, research, organizational structures, staffing matters and the management of funds and properties.

\section{TRAVELLING IDEAS: APPROACHES TO QUALITY ISSUES}

The quality assurance processes in the developed world for teaching and research have been designed to perform various bureaucratic, political and developmental functions (Ashcroft and Foreman-Peck, 1995). These include:

- Processes to ensure minimum standards

- Processes to measure volume

- Processes to rank excellence

- Processes to foster improvement.

\section{Processes to Ensure Minimum Standards}

Processes to measure standards are the cornerstone of higher education quality systems throughout the world. In most systems such processes are considered essential (though some would consider them insufficient) to ensure the quality of education and educational services provided by higher education institutions. Institutions can ensure that programs of study meet minimum standards through a variety of internal mechanisms that include checks against benchmarks, validation and review checklists and so on.

Harvey (1995) suggests that standards may be expressed in various ways: academic standards (for example, students fulfilling the requirements of the course); standards of competence (such as the achievement of key skills); and service standards (for example, student charters). In the UK it is argued that standards (academic, competence, service, and so on) can only be defined within the context of an institution's mission. Thus, a new university with a specific vocational mission and niche market might wish to set different standards of competence from a researchfocused university: for example stressing practical skills rather than theoretical knowledge.

The 2009 Proclamation creates some expectations on universities and the sector as a whole regarding the setting and monitoring of standards: for example, it specifies that institutions in Ethiopia shall have a curriculum development framework and implies that there will be some central guidance on curriculum and standardization through peer panels within subjects. It also has a section on quality enhancement that includes the requirement for institutions to develop internal quality standards and undertake quality audits of these.

\section{Processes to Measure Volume}

Some of the indicators used in quality assessments in developed countries are measures of volume. Examples of these are numbers of students recruited relative to those completing each year of a program and graduating; numbers obtaining employment on graduation; and numbers 
completing programs successfully from certain underrepresented groups. These measures do not look at quality itself, but have some validity as indicators of quality.

As yet, Ethiopia has not developed its quality framework to take real account of these measures. For a while, the Government considered the notion of a funding formula to distribute funding that took some outcome measures into account (completions, but not employment) - see Ashcroft (2005 and 2008). As yet this has not been implemented and the 2009 Proclamation seems to indicate that funding will be based on strategic plans (i.e. an input measure) rather than outcomes, and thus will not be related to quality, however indirectly. However, it specifies that there will also be set standards for the qualification levels of staff that every institution will have to comply with and the accreditation criteria for private universities include a range of quantitative measures in terms (for instance) of numbers of students and programs that indirectly indicate quality: measures of volume being some sort of proxy for capability. The validity of these as indicators of quality is, of course, contestable.

\section{Processes to Rank Excellence}

Research assessment exercises are one way of fulfilling the intention of ranking of excellence and so ensuring that differential funding follows quality of output. In the UK, teaching quality reviews conducted by the Quality Assurance Agency (roughly equivalent to the HERQA in Ethiopia) were not originally planned as a ranking exercise, but rather a means of auditing quality within each institution against its expressed mission and objectives. However, during the late 1990s, scores for different aspects of provision were added together to create quality rankings. More recently, these scores have been combined with other sorts of performance data to create ranking of institutions themselves that have been published by newspapers in the form of league tables. These have a profound influence on academic and institutional behaviours and many researchers have questioned their validity and utility. Since such league tables are comparing institutions against different yard sticks (their missions) and the league tables add together scores for items that have completely different values for different audiences (for example employment outcomes of graduates and research ratings) as if they are equal, these criticisms are justified (see for example, Bowden, 2000).

The HERQA in Ethiopia has developed a process that results in a narrative account of each institution's strengths and weaknesses. For the first few years, apart from listing the numbers of commendations and recommendations, there was no attempt to turn this narrative into quantitative scores, which might be compiled into a league table, and indeed there did not seem to be an intention to do so. Thus, the Ethiopian Government and higher education system at first seemed to have recognised the problems and did not attempt to make such spurious comparisons between institutions, never mind to create league tables. More recently, there are indications that this is one aspect of the quality assurance idea that has (perhaps unfortunately) "travelled". There have been indications of government ambivalence about the private sector that we have discussed in other contexts (see for example, Ashcroft, 2011). More recently, under instructions from the Government HERQA has visited all private higher education institutions and graded them on a four-point scale, with those at the bottom having their accreditation withdrawn. Surprisingly, the results of this exercise have not been published so that students can have more information as to which are the "quality" institutions. 


\section{Processes to Foster Improvement}

Quality activity often aims to enhance quality either as its primary motivation or as a side effect of the reflection on data compiled. The HERQA has been encouraging institutions to develop systems for quality enhancement to operate alongside those for quality control and assurance. Ethiopia has not resolved whether accountability should be the main driver of the quality assurance process or whether it should be quality and/or quality enhancement. If this second idea is to become dominant, then, the subsystem should not remain overly concerned with compliance with standards and rules. However, there are risks in a system such as the Ethiopian one, where instances of poor quality provision are not rare. In the early stages, the HERQA has focused on questions of "Is it good enough?". However, it has not ignored those of "How might it be made better?". The recommendations contained within each HERQA external audit report focus very much on this aspect and, if taken seriously by institutions, should provide a blueprint for the enhancement of standards and quality, or in the short term and at a time of rapid expansion, at least mitigate the effects on quality of over-stretched human and other resources.

\section{ETHIOPIA'S RESPONSE TO THE ISSUE OF QUALITY ASSURANCE}

One of the problems with greater autonomy is that it makes it difficult for the Ministry of Education to supervise and monitor the ways that higher education institutions tackle problems of quality and relevance, equity, resource constraints and utilization.

In 2003, HERQA was a new organisation, quality assurance a new concept to Ethiopian higher education, and so the Agency was faced with the task of establishing what quality meant in the Ethiopian context. Using development organisations such as the World Bank, VSO and NUFFIC (see for example, Ashcroft, 2003; World Bank, 2004; and Rayner, 2005 and 2006), the Ministry of Education sought the help of northern experts in developing appropriate concepts and models of quality that would work for Ethiopian Higher Education.

Yizengaw (2004) describes the reform processes as going through 3 stages:

- Policy and strategy adoption, especially the legal framework

- Rehabilitation and expansion of facilities

- Improvement and revitalization of the system.

The last of these depends upon the development of quality assurance systems: Ethiopia's education and training policy stresses improvements in the quality of staff; learning processes; management and leadership; financial management; quality assurance, autonomy and accountability and the involvement of stakeholders.

The focus on quality in Ethiopia also encompasses relevance, so that students have practical problem-solving skills as well as theoretical knowledge. This requires improvements to teaching and research, greater responsiveness to the labour market and careful curricula review in terms of relevance to Ethiopia's needs. Another focus, student and community orientation, also relates to relevance. This encompasses active learning and practical education/training for almost all students and disciplines throughout their courses and more student involvement in matter such as evaluation and governance.

Many of these reforms were established in law through the Ethiopian Government's 2003 Higher Education Proclamation and are enshrined in the 2009 Higher Education Proclamation. In 
short, apart from the residual power of veto over HEIs" Boards recommendation as to Head and Vice Head of the higher education institution by the Ministry of Education, the 2003 Higher Education Proclamation gave the HEIs considerable autonomy for their own affairs. It also created many of the conditions for a market-orientation: students who pay for part of their education will see themselves as customers who have rights; income generation also demands a market orientation; students who are selected by the institution must be attracted to it otherwise other institutions will also "select" them. The Government that has granted institutional autonomy will need assurance that its money continues to be well spent and so on.

The three major thrusts of the reforms: increases in student numbers, more institutional autonomy and greater market-focus, required a focus on quality. If they are not to be interpreted as license, they imply a system of accountability to ensure the responsible exercise of autonomous decision-making and "value-for-money" in relation to public funds. Students, commercial partners and other stakeholders (including Government) are investing more in higher education for example, through cost sharing, consultancy and funded research, and want to see evidence of quality in "value for money" assessments.

\section{METHODS TO MEASURE QUALITY}

When HERQA was set up, it could have taken various approaches to the measurement of quality from the northern context. These are closely related to the purposes of quality assurance, discussed in some detail above. Thus, the first of these is to measure volume. This method relies on quantitative data collection that is generally poor in Ethiopia, but it can be useful to indicate how much activity occurs and is completed in a system. Of course, such measurement can only indicate quality when interpreted carefully. It is useful for bureaucratic purposes such as accreditation and it allows quantitative data to be compared in a way that looks as if it is objective. As mentioned above, HERQA does indeed look at matters such as student numbers, courses and subjects opened and run to completion and matters of resources when determining whether a private institution may receive accreditation. However sophisticated analysis of this data by HERQA, the Ministry of Education or any other organization is still at a very early stage, although Tamrat (2011) has published a useful piece of research about relationships between HERQA and the private sector.

In relation to quality assessment rather than accreditation, HERQA has located responsibility with the institutions and sees its role as one of supporting the HEIs and auditing institutional systems to determine whether they represent good practice and are fit for purpose as well as suggesting ways for improvement. In doing this it has established certain expectations of institutions that are drawn from ideas first established in northern contexts, sometimes from industry rather than higher education. The first of these ideas is the use of performance indicators (see for example, Barnetson and Cutright, 2000). A major process of business processes reengineering has been undertaken by the Ethiopian higher education system, overseen by HESC. As part of this, HEIs are expected to benchmark their own performance in administrative and academic areas against national and international best practice and come up with plans for improvements. HERQA also expects them to analyze and use this data for quality improvement. Thus, HEIs compare themselves with achievements of others and set targets to improve. This again is a radical and sophisticated exercise to undertake and HEIs, at the time of writing, struggle to do this. 
A central concept that has been developed by HERQA stems from the Dutch and UK quality assurance systems that are based on self-evaluation and external review. In the Ethiopian model, this involves the HEI completing a comprehensive self-evaluation document that should highlight strengths and weaknesses within the institution. Then the documents are ready for some person(s) coming into the institution from the outside world and commenting upon the veracity and depth of the self evaluation as well as what is going on in terms of teaching and learning and research. These people are a mixture of peers from other HEIs working with HERQA professionals. They use a checklist which is based in part on those from the UK, but has been developed and refined in workshops of staff from Ethiopian HEIs. Thus the main feature of the system is self-evaluation and peer review against peer generated criteria, and in this sense it can be seen as a democratic system.

However, participation in these workshops was limited to three main stakeholders, HERQA, the HEIs and the Government, and the views of other stakeholders, particularly students and employers were not represented. This in part is due to the fact that both employers and students are not currently sufficiently organized in Ethiopia. Unlike the UK for example where the CBI (Confederation of British Industries) provides a strong lobby on behalf of employers on matters relating to higher education, there is no one organization able to represent the interests and needs of major businesses. It is possible therefore, that a different set of stakeholders might have had a different set of priorities and produced a different checklist against which HEIs are judged.

Ethiopian HEIs are also being encouraged to introduce external and second examiner systems, external representation on course validation and periodic course review panels as other ways of measuring their own quality for their internal and external purposes. This is an idea that related closely to quality assurance systems in the UK and The Netherlands and which has been encouraged especially by the VSO "travelling salesmen" mentioned above. Thus, over the last few years, Ethiopia's system of measuring quality has been based on a quality assurance model that assumes HEIs have some degree of autonomy and have quality systems in place. Auditors then visit and assess the extent to which these are (a) used and understood by all, and (b) are adequate.

\section{CONCLUSION}

There have been a range of influences on Ethiopia's system of quality assurance with consultants and others from the World Bank, NUFFIC and VSO amongst others, whether intentionally or not, acting as "travelling salesmen" for their own systems. The Ethiopian Government, HEIs and HERQA have generally been astute in assessing which ideas to adopt and in adapting them to the country's culture and needs. However, there is an element of chance in the fact that these particular "travelling salesmen" were the ones in a position to influence the development of quality assurance in Ethiopia. This is largely because these donors, the World Bank, VSO and NUFFIC, include higher education as part of their remit. If, for example the USA had prioritised higher education rather than basic education in Ethiopia, then it might be that the "travelling salesmen" would have promoted the American model of quality assurance for higher education, which would have probably produced very different results.

We have discussed elsewhere the dilemmas raised by the importation of concepts, ideas and practices from northern to developing contexts (see Ashcroft and Rayner, 2011). Despite these problems, it seems as if Ethiopia's higher education system for quality assurance in higher 
education has developed a settled conceptual and philosophical framework. There is a consensus about its essential features:

- Institutions' autonomy should be respected

- HERQA's role is to look for and value local innovation and then disseminate results

- The institution takes responsibility for designing good quality processes and outcomes, rather than HERQA prescribing a set of inputs (e.g. curricula content or types of assessment)

- The HEI's mission and objectives are the starting point for assessment

- The system assumes most of the innovatory ideas and improvements in quality systems will come from HEIs rather than the HERQA

- HERQA's job is not to control, but to recognize and disseminate these

- Institutional self-assessment of their own strengths and weaknesses is expected to lead HEIs to seek and implement improvements

- The system relies on skills of self assessment that generally require some training: this is supplied regularly by HERQA

- HEIs trust that they will get a better report where they have identified their own weaknesses and the ways in which they will rectify them.

Some ideas from northern partners have been largely rejected. For example, there is consensus that HEIs will not honestly self-assess in a context of league tables and intense competition and therefore there has been no attempt to import the more extreme forms of the quasi-market into higher education. Ethiopia's system is not directed at any over-riding need to protect diversity. It assumes a notion of "fitness for purpose" which is compatible with largely centralized development of curricula, although processes and standards of outcome are almost entirely within institutional control.

The issue of whether inspectorates are to be seen as a threat to autonomy and therefore to be avoided has not yet been fully debated or resolved. The 2009 Higher Education Proclamation suggests that HERQA will take an inspection role with respect to the rest of education. This has not yet been implemented and there is some sign of backtracking from the idea. However, if it were, it might have some backwash effect for the higher education sector. For example the model developed for higher education with its emphasis on academic freedom would not easily transfer to a more rigid secondary sector. There would also be a danger that any addition roles and responsibilities for HERQA would distract from a model that seems to be, at least in its early stages, working well and have the support of the higher education sector. There is also a dire shortage of suitably experienced and qualified staff in Ethiopia to meet current HERQA commitments, both for the recruitment of full time "experts" to HERQA and to work as peer reviewers on external audits. Any additional workload could negatively affect the quality of HERQA's own performance. There is also still a question over the autonomy of HERQA itself when the Minister of Education heads its management board. Higher education in Ethiopia has been in a fairly constant state of change and development since the early 1990s and there is no guarantee that HERQA's independence and mode of operation can be maintained if its remit were to be extended to cover the whole of the education sector.

The Government of Ethiopia has taken a brave political gamble in going for such rapid higher education expansion and again in setting up HERQA. It risks exposing a range of contradictions and dilemmas that Ethiopia faces, for example, between control and autonomy, 
modernisation and "government knows best", democracy and the need to control dissident voices. However, the resulting debate is likely to enrich the development of the system and reflect the dilemmas that inevitably arise within institutions themselves because of these tensions and the need for managers to work out the hidden as well as overt agendas. It is becoming clearer which of the original ideas should be rejected, which might be salvaged and which have been added and improved by Ethiopian adaptations.

\section{REFERENCES}

Ashcroft, K. (2003). "Emerging Models of Quality, Relevance and Standards in Ethiopia's Higher Education Institutions". The Ethiopian Journal of Education, 23(2): 1-26.

Ashcroft, K. (2005). The Introduction of a Funding Formula for Teaching and Learning in Higher Education Institutions in Ethiopia, National Report to the Federal Government of Ethiopia, Addis Ababa: Higher Education Strategy Centre.

Ashcroft, K. (2005). A Framework for the Development of 13 New University Colleges in Ethiopia: options as to growth, staffing, funding, management, course offerings and qualifications structures, National Report to the Federal Government of Ethiopia, Addis Ababa: Higher Education Strategy Centre.

Ashcroft, K. (2008). Towards an Implementation Strategy for the Funding Formula for Higher Education, Ethiopian Higher Education Strategy Centre, Addis Ababa.

Ashcroft, K. (2011). Africa: Dilemmas of Development Work, University World News, http://www.universityworldnews.com/article.php?story=20100903174508343. Accessed on Oct. $16,2011$.

Ashcroft, K. and Foreman-Peck, L. (1995). The Lecturer's Guide to Quality and Standards in Colleges and Universities, London and Washington: The Falmer Press.

Ashcroft, K. and Rayner, P. (2011). Higher Education in Development: Lessons from Sub Saharan Africa, Chicago: Information Age Publishing.

Barnetson, B. and Cutright, M. (2000), Performance Indicators as Conceptual Technologies. Higher Education, 40(3): 277-292.

Bowden, R. (2000). Fantasy Higher Education, University and College League Tables. Quality in_Higher Education. 6(1): 41-60.

Brown, R. (2001). Accountability in Higher Education, the Case for a Higher Education Audit Commission. Higher Education Review. 33(2): 5-20.

Federal Democratic Republic of Ethiopia (1997). Future Directions of Higher Education in Ethiopia, Addis Ababa: Ministry of Education. 
Federal Democratic Republic of Ethiopia (2002a). Capacity Building Strategy and Program, Addis Ababa: Ministry of Education.

Federal Democratic Republic of Ethiopia (2002b). Sustainable Development and Poverty Reduction program, Addis Ababa: Ministry of Finance and Economic Development.

Federal Democratic Republic of Ethiopia (2003). Proclamation No. 351/2003; Higher Education Proclamation. Addis Ababa: Negarit Gazette.

Federal Democratic Republic of Ethiopia, (2005a). Education Sector Development Program III (ESDP III), Addis Ababa: Ministry of Education.

Federal Democratic Republic of Ethiopia (2005b). Plan for Accelerated and Sustained Development to End Poverty (PASDEP), Addis Ababa: Ministry of Finance and Economic Development.

Federal Democratic Republic of Ethiopia (2009). Proclamation No. 650/2009; Higher Education Proclamation. Addis Ababa: Negarit Gazette.

Harvey, L. (1995). Editorial. Quality in Higher Education. 1(1): 190-114.

HEFCE (2008). How the HEFCE Allocates its Funds. 08/33, Bristol: Higher Education Funding Council for England.

International Network for Quality Assurance Agencies in Higher Education (INQAAHE) (2009). Program for Quality Assurance Professionals (QAP) Module 1, Unit 2, http://www.inqaahe.org. Accessed in November 2009.

QAA, (2008). The framework for higher education qualifications in England, Wales and Northern Ireland (FHEQ), Gloucester: Quality Assurance Agency.

Rayner, P. (2006). Quality: An Ideological Construct. Ethiopian Journal of Higher Education, 3(1): 63-101.

Rayner, P. (2005). Quality: A Many-Headed Hydra? Quality Perceptions in the Eyes of Different Stakeholders. Proceedings of the $3^{\text {rd }}$ National Conference on Private Higher Education in Ethiopia, Addis Ababa.

Supply of Goods and Services Act (1982). http://www.berr.gov.uk/whatwedo/consumers/factsheets/page38337.html 19 Aug 2009

Tamrat, W. (2011). Evaluating the Evaluator: HERQA in the eyes of PHEIs in Ethiopia, paper presented at the HERQA Conference "The influence of HERQA on the Quality and Relevance of Ethiopia's Education System: Reflections on the Evidence", May 3-4, 2011, Addis Ababa, Ethiopian Management Institute. 
UNESCO (2011). http://stats.uis.unesco.org/unesco/TableViewer/

World Bank (2004). Higher Education Development for Ethiopia: Pursuing the Vision, Washington: World Bank.

Yizengaw, T. (2004). The Status and Challenges of Ethiopian Higher Education System and its Contribution to Development. The Ethiopian Journal of Higher Education 1 (1): 6-49.

Yizengaw, T. (2007a). The Ethiopian Higher Education: Creating Space for Reform, Addis Ababa: St.Mary's University College Press.

Yizengaw, T. (2007b). Government Policies and Institutional Responsibilities of PHEIs.

Proceedings of the $5^{\text {th }}$ National Conference on Private Higher Education Institutions in Ethiopia, Addis Ababa: St. Mary's University College Press. 